\title{
The Inhibitory Effects of HYDAMTIQ, a Novel PARP Inhibitor, on Growth in Human Tumor Cell Lines With Defective DNA Damage Response Pathways
}

\author{
Enrico Mini,* Ida Landini,* Laura Lucarini, $\dagger$ Andrea Lapucci, $*$ Cristina Napoli, \\ Gabriele Perrone, ${ }^{*}$ Renato Tassi, ${ }^{*}$ Emanuela Masini, $\dagger$ Flavio Moroni, $\dagger$ and Stefania Nobili \\ *Department of Experimental and Clinical Medicine, University of Florence, Florence, Italy \\ $\dagger$ Department of NEUROFARBA, University of Florence, Florence, Italy \\ $\$$ Department of Health Sciences, University of Florence, Florence, Italy
}

\begin{abstract}
The poly(ADP-ribose) polymerase (PARP) enzymes play a key role in the regulation of cellular processes (e.g., DNA damage repair, genomic stability). It has been shown that PARP inhibitors (PARPIs) are selectively cytotoxic against cells having dysfunctions in genes involved in DNA repair mechanisms (synthetic lethality). Drug-induced PARP inhibition potentiates the activity of anticancer drugs such as 5-fluorouracil in enhancing DNA damage, whose repair involves PARP-1 activity. The aim of this study was to evaluate the inhibitory effects of a novel PARPI, HYDAMTIQ, on growth in human tumor cell lines characterized by different features with regard to DNA damage response pathways (BRCA mutational status, microsatellite status, and ATM expression level) and degree of sensitivity/resistance to 5-fluorouracil. HYDAMTIQ showed a more potent inhibitory effect on cell growth in a BRCA2 mutant cell line (CAPAN-1) compared with wild-type cells (C2-6, C2-12, and C2-14 CAPAN-1 clones, and MCF-7). No statistically significant difference was observed after HYDAMTIQ exposure between cells having a different MS status or a different MRE11 mutational status. HYDAMTIQ induced greater antiproliferative effects in SW620 cells expressing a low level of ATM than in H630 cells expressing a high level of ATM. Finally, the combination of HYDAMTIQ and 5-fluorouracil exerted a synergistic effect on the inhibition of SW620 cell growth and an antagonistic effect on that of H630 cell growth. Our results show that the novel PARP inhibitor HYDAMTIQ potently inhibits the growth of human tumor cells with defective DNA damage response pathways and exerts synergistic cytotoxicity in combination with 5-fluorouracil. These data provide relevant examples of synthetic lethality and evidence for further development of this novel PARPI.
\end{abstract}

Key words: PARP inhibitors (PARPIs); HYDAMTIQ; 5-Fluorouracil (5-FU); Human tumor cell lines; DNA damage response

\section{INTRODUCTION}

Poly(ADP-ribose) polymerases (PARPs) are a major family of proteins that catalyzes posttranslational modifications [i.e., poly(ADP-ribosyl)ation and mono(ADPribosyl)ation (PARylation and MARylation, respectively) $]^{1}$. Such proteins use the $\mathrm{NAD}^{+}$cofactor to transfer an ADP-ribose group onto a specific protein acceptor with the concomitant release of nicotinamide ${ }^{2}$. Today, at least 17 members of this family of enzymes have been identified. PARPs regulate both nuclear and cytoplasmic processes, including DNA damage repair, transcription, cell cycle progression, unfolded protein response, mitosis, and cell death ${ }^{2}$.

The nuclear members (PARP-1-3) have been reported to be involved in several biological processes, including DNA damage. Since the effects of PARP inhibitors (PARPIs) on cancer cells are related to DNA damage, most research on PARPIs has focused on such PARPs. PARP-1 and PARP-2 synthesize branched PAR polymers, whereas PARP-3 is a critical player in the stabilization of the mitotic spindle and in telomere integrity, notably by associating and regulating the mitotic components NuMA and tankyrase $1^{3}$.

Emerging data suggest that PARP inhibition is a potentially important strategy for managing a significant subset of tumors. The rationale for the use of PARPIs is based on the exploitation of synthetic lethality conferred to cancer cells by the copresence of an aberrant DNA damage response (DDR) gene and the PARPI ${ }^{4}$.

To date, only two PARPIs are approved for clinical use: olaparib and rucaparib. Olaparib received accelerated 
approval by the FDA in pretreated ovarian cancer patients harboring germline BRCA mutations on the basis of favorable objective response rate and duration of response obtained in clinics ${ }^{5}$. Rucaparib has been recently approved for the treatment of platinum-sensitive $B R C A$-mutated advanced ovarian cancer patients who received more than two lines of platinum-based therapy and whose tumors show homologous recombination (HR) loss of heterozygosity $^{6}$. In cells with mutations in BRCA1 and/or BRCA2 that are HR deficient, PARPIs stimulate DNA repair by the error-prone nonhomologous end joining recombination (NHEJ) mechanism. Thus, NHEJ is the major contributor to the cytotoxicity observed in HR-deficient cells treated with PARPIs ${ }^{7}$.

The PARPI HYDAMTIQ, a hydroxyl derivative of thieno[2,3-c]isoquinolin-5(4H)-one, is a potent and selective PARP-1/2 inhibitor ${ }^{8,9}$. The neuroprotective ${ }^{10}$, antiasthmatic ${ }^{11}$, and anti-inflammatory ${ }^{12}$ properties of HYDAMTIQ have been investigated in in vivo experimental systems in relation to the fact that PARP-1 activation contributes to postischemic brain damage and facilitates the expression of tumor necrosis factors and other proinflammatory cytokines.

The present research investigates the potential anticancer activity of HYDAMTIQ by studying the inhibitory effects of HYDAMTIQ on the growth of a panel of human cancer cell lines characterized by differences in the mutational status of BRCA gene, microsatellite status, expression levels of ATM (ataxia-telangiectasia mutated), and degree of intrinsic sensitivity/resistance to 5-fluorouracil (5-FU).

Cell lines received long-term exposure to HYDAMTIQ in order to closely mimic the exposure times that derive from the continuous oral administration of olaparib in clinics ${ }^{13,14}$.

\section{MATERIALS AND METHODS}

\section{Drugs and Supplies}

Olaparib was obtained from Selleck Chemicals (Munich, Germany); the novel PARPI HYDAMTIQ was provided by Prof. Pellicciari (University of Perugia) and TESPHARMA (Perugia, Italy). 5-FU and sulforhodamine B (SRB) were obtained from Sigma-Aldrich (Milan, Italy). All the other chemicals were of analytical grade. RPMI-1640 and high-glucose DMEM cell culture mediums, fetal calf serum (FCS), trypsin-EDTA, antibiotics, and phosphate-buffered saline were obtained from Gibco (Milan, Italy).

The phospho-ATM (Ser1981) mouse monoclonal antibody was obtained from GeneTex (Irvine, CA, USA) and Alexa Fluor ${ }^{\circledR} 488$ and 4,6-diamidino-2 phenylindole (DAPI) were from Abcam (Cambridge, UK).

\section{Cell Lines and Culture Conditions}

The human BRCA2-mutated pancreatic cancer cell line (CAPAN-1) sensitive to cisplatin and its clones (C2-6,
C2-12, and C2-14) characterized by secondary intragenic mutations in BRCA2 that restore the wild-type BRCA2 reading frame and that confer resistance to cisplatin were a gift from Dr. Toshiyasu Taniguchi (Fred Hutchinson Cancer Research Center, Seattle, WA, USA). The breast cancer cell line MCF-7 (BRCA1/2 wild type) and the colorectal cancer cell lines HCT-8, HCT-116, H630, LoVo, DLD-1 [microsatellite instable (MSI)], HT29, and SW620 [microsatellite stable (MSS)] were obtained from ATCC) (Manassas, VA, USA). Cell lines were maintained in an appropriate culture medium (RPMI-1640 or high-glucose DMEM), supplemented with $10 \%$ FCS and antibiotics (penicillin, $100 \mathrm{U} / \mathrm{ml}$; streptomycin, $100 \mu \mathrm{g} / \mathrm{ml}$ ) at $37^{\circ} \mathrm{C}$ in a $5 \% \mathrm{CO}_{2}$ humidified atmosphere and subcultured twice weekly.

\section{Cell Growth Inhibition Studies}

The antiproliferative effects of HYDAMTIQ and olaparib were evaluated on the growth of the studied human tumor cell lines by the SRB assay ${ }^{15}$. Briefly, exponentially growing cells were inoculated into 96-well microtiter plates at plating densities of $2 \times 10^{3}$ cells/well. After cell inoculation, the microtiter plates were incubated under standard culture conditions $\left(37^{\circ} \mathrm{C}, 5 \% \mathrm{CO}_{2}\right.$, $95 \%$ air, and $100 \%$ relative humidity) for $24 \mathrm{~h}$ prior to the addition of experimental drugs. After $24 \mathrm{~h}$, the medium was removed and replaced with medium containing PARPIs at concentrations ranging from 0.5 to $50 \mu \mathrm{M}$ for continuous exposures of 72,144 , or $240 \mathrm{~h}$. The assay was completed by the addition of cold TCA. Cells were fixed in situ by $10 \%$ TCA and stained by SRB solution at $0.4 \%(\mathrm{w} / \mathrm{v})$ in $1 \%$ acetic acid. After staining, unbound dye was removed by washing five times with $1 \%$ acetic acid, and the plates were air dried. Bound stain was subsequently solubilized with $10 \mathrm{mM}$ Tris base, and the absorbance was read on an automated plate reader at a wavelength of $540 \mathrm{~nm}$.

The $\mathrm{IC}_{20}, \mathrm{IC}_{25}$, and $\mathrm{IC}_{50}$ resulting in a $20 \%, 25 \%$, and $50 \%$ reduction in the net protein content (as measured by SRB staining) in drug-treated cells compared to untreated control cells were determined after drug exposures.

The degree of resistance $(R)$ to PARPIs is defined as the ratio between $\mathrm{IC}_{50}$ values obtained in $B R C A 1 / 2$ mutated, MSI, or lowest-ATM expression cell lines and the $B R C A 1 / 2$ wild type, MSS, and highest-ATM expression cell lines, respectively. $R$ values lower than 0.9 indicate collateral sensitivity, and those between 0.9 and 1.1 equal sensitivity and $R$ values higher than 1.1 indicate cross-resistance ${ }^{16}$.

The growth inhibitory effects of the combination of PARPIs and 5-FU on SW620 and H630 have been studied using the $\mathrm{IC}_{25}$ of 5-FU (1 and $3 \mu \mathrm{M}$ for H630 and SW620 cells, respectively) and the $\mathrm{IC}_{50}$ of HYDAMTIQ (20 and $45 \mu \mathrm{M}$ for SW620 and H630 cells, respectively) 
or of olaparib (5 and $30 \mu \mathrm{M}$ for SW620 and H630, respectively) and by exposing cells to drugs for $144 \mathrm{~h}$.

The potential synergism between HYDAMTIQ and 5-FU was evaluated using Drewinko's fraction method ${ }^{16}$. The synergistic, additive, and antagonistic interactions were determined by the ratio between the cell growth following single-agent exposures (expected value) and the cell growth following drug-combination exposures (observed cell growth) (CI) as follows: $\mathrm{CI}<0.9$ synergism, CI from 0.9 to 1.1 additivity, and CI $>1.1$ antagonism.

\section{Immunofluorescence Analysis}

Immunofluorescence analysis of baseline ATM protein levels was performed in duplicate in five human colon carcinoma cell lines (HCT-8, H630, SW620, LoVo, and HT29). By densitometry analysis of protein levels, the cell lines with the highest and lowest level of ATM were identified (H630 and SW620, respectively). Such cell lines were used in the experiments of expression modulation after long-term exposure $(240 \mathrm{~h})$ at $2 \times \mathrm{CI}_{50}$ of HYDAMTIQ.

Cells were grown in glass chamber slides at a starting concentration of $0.75 \times 10^{4}$ in $0.5 \mathrm{ml}$ of complete culture medium for 4-5 days until confluence. Slides were washed twice with cold PBS and then fixed with cold $100 \%$ methanol for $10 \mathrm{~min}$ at $-20^{\circ} \mathrm{C}$. Cells were then permeabilized with $0.1 \%$ Triton X-100 in PBS for 15 min.

After washing three times with PBS, the slides were blocked for $30 \mathrm{~min}$ in PBS containing 2\% BSA at room temperature, and then incubated for $1 \mathrm{~h}$ with 1:1,000 dilution of phospho-ATM(Ser1981) antibody in 2\% BSA/ PBS. After several washings with $0.1 \%$ Tween $20 / \mathrm{PBS}$, bound antibodies were detected with a 1:200 dilution of goat anti-mouse secondary polyclonal antibody, FITC) conjugate (Abcam). Nuclei were counterstained with a 1:5,000 dilution of DAPI for $15 \mathrm{~min}$. Representative images were acquired by an Olympus BX63 microscope coupled with a CellSens Dimension Imaging Software version 1.6 (Olympus, Milan, Italy).

The fluorescence intensity was determined in a semiquantitative way with densitometry analysis (ImageJ software, NIH Image) normalizing for the number of cells per microscope field.

\section{Statistical Analysis}

Statistical analysis was performed employing Student's $t$-test and Spearman test (GraphPad Prism v.5). Values of $p<0.05$ were considered significant.

\section{RESULTS}

HYDAMTIQ Inhibitory Effects on the Growth of Tumor Cell Lines With Different Mutational Status of BRCA2

The inhibitory effects of HYDAMTIQ and olaparib were evaluated in the BRCA2-mutated CAPAN-1 cell lines, its C2-6, C2-12, and C2-14 clones characterized by secondary intragenic mutations in $B R C A 2$ that restore the wild-type $B R C A 2$ reading frame, and in the $B R C A 2$ wild-type MCF-7 cells after 72, 144, and $240 \mathrm{~h}$ of exposure. Slightly higher $\mathrm{IC}_{50}$ values were observed with HYDAMTIQ compared with olaparib after 72 or $144 \mathrm{~h}$ of treatment, whereas after $240 \mathrm{~h}$ HYDAMTIQ and olaparib showed similar $\mathrm{IC}_{50}$ values (Table 1).

At all exposure times, HYDAMTIQ was significantly more active at inhibiting CAPAN-1 cell growth compared to C2-6, C2-12, and C2-14 BRCA2 wild-type clones. Resistance ratio $(R)$ values ranged from 1.8 to 2.1 after 72 and $144 \mathrm{~h}$ and from 2.0 to 2.4 after $240 \mathrm{~h}$ of exposure. Similarly, HYDAMTIQ was more active in CAPAN-1 cells than in MCF-7 cells. $R$ values ranged from 2.7 and 5.6 after all the interval exposure times were tested. Overall, a time-dependent inhibitory effect on cell growth was observed. Lower $\mathrm{IC}_{50}$ values were associated with prolonged time of exposure $(p<0.05)$. A similar trend was observed for olaparib $(p<0.05)$ (Table 1$)$. The inhibitory effects of olaparib on cell growth compared to HYDAMTIQ were more marked following 72 and $144 \mathrm{~h}$ of treatment, whereas after $240 \mathrm{~h}$ the $\mathrm{IC}_{50}$ values of the two drugs were similar.

\section{HYDAMTIQ Inhibitory Effects on the Growth of Tumor Cell Lines With Different Status of Microsatellites}

The $\mathrm{IC}_{50}$ values of HYDAMTIQ and olaparib in the microsatellite stable HT29 and SW630 cell lines (MSS) have been compared with those obtained in the microsatellite instable HCT-8, HCT-116, LoVo, and DLD-1 cell lines (MSI). No statistically significant difference was observed after 144 (data not shown) or $240 \mathrm{~h}$ of exposure to HYDAMTIQ or olaparib between cells with different MS status (Fig. 1). Furthermore, no difference was observed in such cell lines according to the MRE11 mutational status (Fig. 1).

\section{HYDAMTIQ Inhibitory Effects on the Growth of Tumor Cell Lines With Variable Levels of ATM Protein}

A panel of colorectal cancer cell lines (HCT-8, H630, SW620, LoVo, and HT29) was analyzed for ATM protein expression levels by immunofluorescence assay. Among the colorectal cancer cell lines, a high degree of variability in ATM protein expression was observed. In particular, H630 cells had the highest level of ATM protein and SW620 cells the lowest (H630 > HCT-8 > HT29>LoVo> SW620) (Fig. 2).

Relationships between $\mathrm{IC}_{50}$ values of HYDAMTIQ or olaparib obtained at 144 and $240 \mathrm{~h}$ in the five colorectal cancer cell lines and ATM protein expression levels were investigated. Direct associations were observed for all the comparisons performed, and statistically significant values were obtained between 144-h $\mathrm{IC}_{50}$ of HYDAMTIQ and ATM level ( $p=0.0167)$ and between 144-h (Fig. 3A and C) 
Table 1. Inhibitory Effects of HYDAMTIQ and Olaparib on Cell Growth of Tumor Cell Lines With Different BRCA1/2 Mutational Status After 72, 144, and $240 \mathrm{~h}$ of Exposure

\begin{tabular}{|c|c|c|c|c|c|c|}
\hline & \multicolumn{3}{|c|}{ HYDAMTIQ, $\mathrm{IC}_{50}(\mathrm{mM}) \pm \mathrm{SE}$} & \multicolumn{3}{|c|}{ Olaparib, $\mathrm{IC}_{50}(\mathrm{mM}) \pm \mathrm{SE}$} \\
\hline & $72 \mathrm{~h}$ & $144 \mathrm{~h}$ & $240 \mathrm{~h}$ & $72 \mathrm{~h}$ & $144 \mathrm{~h}$ & $240 \mathrm{~h}$ \\
\hline $\begin{array}{l}\text { CAPAN-1 } \\
n\end{array}$ & $\begin{array}{c}16.8 \pm 0.3 \\
3\end{array}$ & $\begin{array}{l}5.4 \pm 0.1 \\
3\end{array}$ & $\begin{array}{l}1.9 \pm 0.1 \\
3\end{array}$ & $\begin{array}{l}9.4 \pm 0.8 \\
3\end{array}$ & $\begin{array}{l}2.4 \pm 0.1 \\
3\end{array}$ & $\begin{array}{l}1.9 \pm 0.1 \\
3\end{array}$ \\
\hline CAPAN-1 C2-6 & $30.2 \pm 1.0$ & $9.7 \pm 0.8$ & $4.3 \pm 0.2$ & $13.3 \pm 0.8$ & $5.6 \pm 0.2$ & $4.4 \pm 0.3$ \\
\hline$r$ & 1.8 & 1.8 & 2.3 & 1.4 & 2.4 & 2.4 \\
\hline$n$ & 3 & 3 & 3 & 3 & 3 & 3 \\
\hline$p$ & 0.002 & 0.037 & 0.002 & 0.146 & 0.0010 & 0.011 \\
\hline CAPAN-1 C2-12 & $33.7 \pm 1.3$ & $11.6 \pm 1.0$ & $4.5 \pm 0.1$ & $15.1 \pm 0.3$ & $7.7 \pm 0.2$ & $4.3 \pm 0.1$ \\
\hline$r$ & 2.0 & 2.1 & 2.4 & 1.6 & 3.3 & 2.3 \\
\hline$n$ & 3 & 3 & 3 & 3 & 3 & 3 \\
\hline$p$ & 0.002 & 0.023 & 0.001 & 0.016 & 0.0001 & 0.0006 \\
\hline CAPAN-1 C2-14 & $34.5 \pm 1.0$ & $9.7 \pm 0.4$ & $3.9 \pm 0.1$ & $18.5 \pm 2.0$ & $7.6 \pm 0.2$ & $3.1 \pm 0.2$ \\
\hline$r$ & 2.1 & 1.8 & 2.0 & 1.5 & 2.9 & 1.8 \\
\hline$n$ & 3 & 3 & 3 & 3 & 3 & 3 \\
\hline$p$ & 0.001 & 0.004 & 0.001 & 0.004 & $<0.0001$ & 0.042 \\
\hline MCF-7 & $44.7 \pm 2.6$ & $30.4 \pm 3.4$ & $8.3 \pm 0.9$ & $26.1 \pm 0.6$ & $19.9 \pm 0.9$ & $3.3 \pm 0.3$ \\
\hline$r$ & 2.7 & 5.6 & 4.4 & 2.8 & 8.4 & 1.8 \\
\hline$n$ & 4 & 4 & 3 & 4 & 4 & 3 \\
\hline$p$ & 0.007 & 0.026 & 0.026 & 0.003 & 0.004 & 0.054 \\
\hline
\end{tabular}

$\mathrm{IC}_{50}$, concentration of drug required to inhibit cell growth by $50 \%$; SE, standard error; $r$, resistance index; $n$, number of experiments; $p$, HYDAMTIQ or olaparib $\mathrm{IC}_{50}$ values of CAPAN- 1 cells versus CAPAN- 1 clones or MCF-7 cells.

or 240-h (Fig. 3B and D) $\mathrm{IC}_{50}$ of olaparib and ATM level ( $p=0.0167$ in both cases).

Different sensitivities of colorectal cancer cells to PARPIs according to ATM levels is shown in Figure 4. Resistance values given by the ratio of the highest ATM expression cells (H630) over the lower ATM expression cells (SW620) after $240 \mathrm{~h}$ of treatment with HYDAMTIQ or olaparib were 0.5 and 0.3 , respectively (Fig. 4 A and B).
After $144 \mathrm{~h}$ of treatment with HYDAMTIQ or olaparib, the $r$ values according to the same parameters were 0.4 and 0.3 , respectively (data not shown).

In order to investigate the relationships between PARP inhibition and ATM protein expression variability, H630 and SW620 cells were exposed to a double $\mathrm{IC}_{50}$ concentration of HYDAMTIQ for $240 \mathrm{~h}$. Comparison of ATM expression levels before and after exposure to
A)

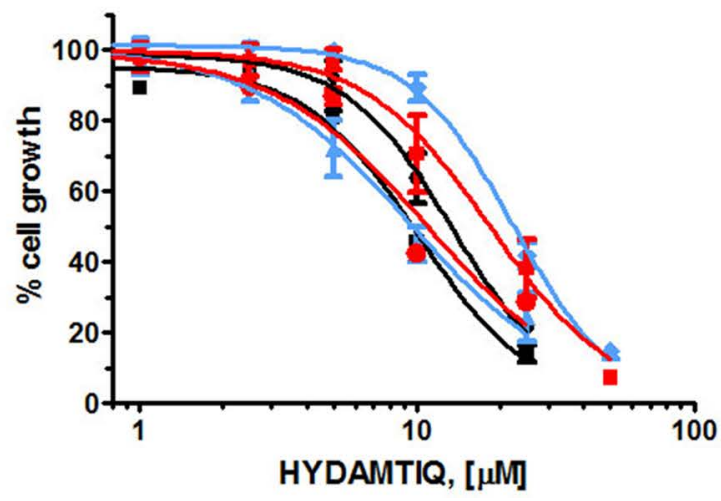

B)

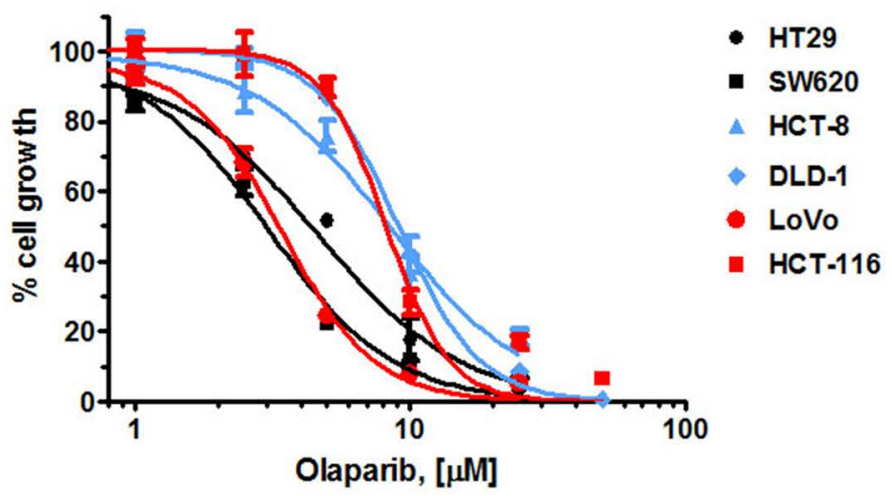

Figure 1. Inhibition of human colon carcinoma cell growth: dose-dependent effects of HYDAMTIQ (A) and olaparib (B). Black curves indicate microsatellite stable (MSS) cell lines [MRE11 wild type (wt)]; blue curves indicate microsatellite instable (MSI) cell lines with heterozygous status of MRE11; and red curves indicate MSI cell lines with homozygous mutational status of MRE11. Each curve indicates the concentration-cell growth inhibition curve of a single cell line following $240 \mathrm{~h}$ of exposure. 
A)

B)

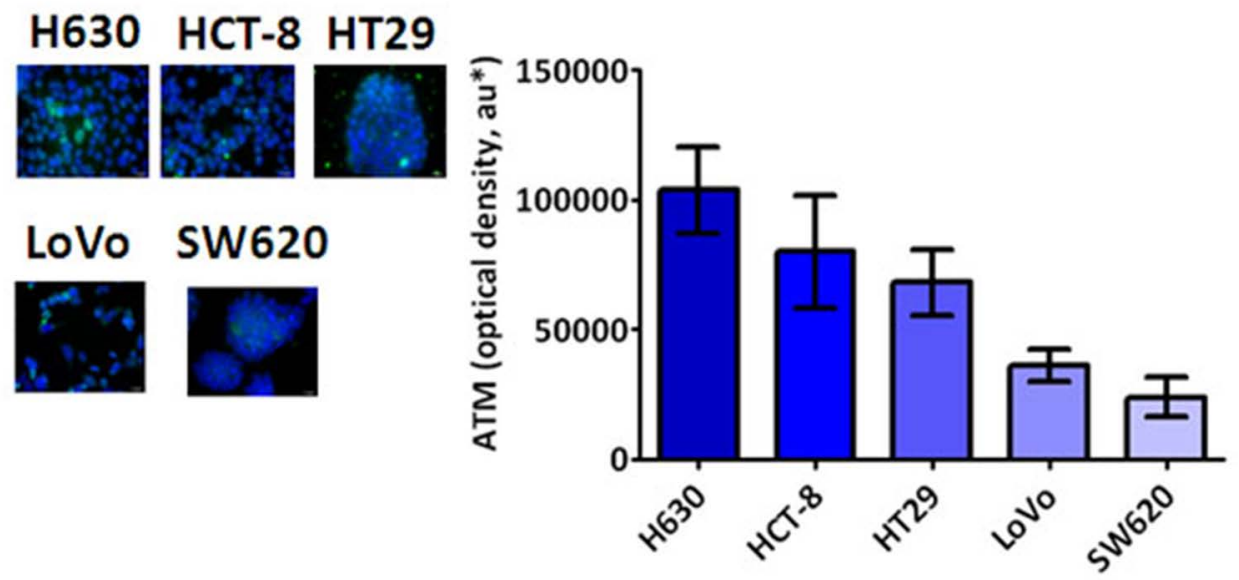

Figure 2. Baseline levels of ATM (ataxia-telangiectasia mutated) protein expression in colon carcinoma cell lines. (A) Immunofluorescence staining of cell lines labeled with anti-ATM polyclonal antibody (green) and nuclei (blue) counterstained with DAPI (4,6diamidino-2 phenylindole) (40×). Images show the baseline levels of ATM in cell lines. ATM plays a critical role in signaling DNA damage to cell cycle checkpoints and DNA repair pathways. (B) Baseline ATM protein level optical density according to the different cell lines tested. *au, arbitrary units, mean \pm standard error.

HYDAMTIQ showed a decrease, although not statistically significant, of intranuclear fluorescent ATM protein in both cell lines (Fig. 4C and D).

\section{Inhibitory Effects of Combined HYDAMTIQ With \\ 5-Fluorouracil on Tumor Cell Lines With High or Low ATM Protein Levels}

H630 and SW620 cells were exposed to 5-FU combined with HYDAMTIQ or olaparib for $144 \mathrm{~h}$. Cell growth inhibition was evaluated using H630 and SW620 $\mathrm{IC}_{25}$ values for 5-FU and $\mathrm{IC}_{50}$ values for HYDAMTIQ or olaparib.

There was a synergistic effect obtained following exposure to both combinations (i.e., HYDAMTIQ/5-FU or olaparib/5-FU, CI: 0.6 or 0.5 , respectively) in SW620 cells, characterized by low ATM level (Fig. 5A and B). On the contrary, according to the same experimental conditions, an antagonistic effect was observed in $\mathrm{H} 630$ cells characterized by high ATM level (CI: 1.3 and 1.6, respectively) (Fig. 5C and D).

\section{DISCUSSION}

PARPs are a superfamily of enzymes involved in the regulation of cellular processes, such as DNA repair, gene transcription, cell cycle progression, cell death and genomic stability, and apoptosis ${ }^{1,17,18}$.

PARP-1 and PARP-2 control single-strand break (SSB) repair systems such as base excision repair (BER) and nucleotide excision repair (NER) pathways ${ }^{19}$. PARP-1 is also involved in the transcription of mitochondrial proteins ${ }^{20}$. In addition, PARP-1, PARP-2, and PARP-3 are involved in double-stranded break (DSB) repair. In particular, PARP-3 has been shown to be involved in DSB repair, mainly promoting the NHEJ process ${ }^{19}$. DNA damage repair systems, together with cell cycle checkpoints, are the cellular reaction to exogenous and endogenous genotoxic injuries that may produce DNA SSBs and DNA DSBs. Overall, DDR plays a pivotal role in maintaining genomic integrity and avoiding the occurrence of genomic instability typical of cancer cells. However, several examples of aberrant proteins are known today [e.g., MRE11 in DSB repair, BRCA1 and BRCA2 in HR repair (HRR), and ATM and ATR (i.e., ATM and RAD3 related) in cell cycle checkpoints $]^{21,22}$. ATM, ATR, and DNA-dependent protein kinases (DNA-PKcs) are the most upstream DDR kinases. In response to DNA damage, several proteins are phosphorylated in an ATM- or ATR-dependent manner, whereas DNA-PKcs regulate a smaller number of targets and play a role, primarily in $\mathrm{NHEJ}^{23}$.

Most PARPIs act as competitive inhibitors of NAD by interfering at the binding site of the enzyme ${ }^{24}$ or trapping PARP enzymes at damaged DNA ${ }^{25}$. In the last few years, a significantly increased potency and selectivity of PARPIs have been obtained because of the advancements in the knowledge of relationships between chemical structures and pharmacological activity ${ }^{26,27}$.

We investigated the antiproliferative properties of the PARPI HYDAMTIQ on the growth of a panel of human tumor cell lines. HYDAMTIQ is a potent inhibitor of PARP-1 and PARP-2 with $\mathrm{IC}_{50}$ values in the nanomolar range ( $\mathrm{IC}_{50} 29$ and $38 \mathrm{nM}$, respectively) ${ }^{9}$. The biological 
A)

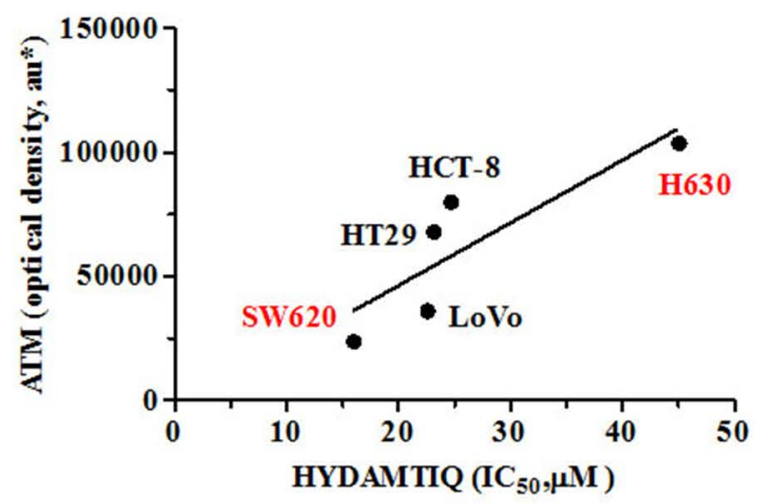

\begin{tabular}{|l|l|}
\hline Spearm an $\mathbf{r}$ & 1.000 \\
\hline P value (two-tailed) & 0.0167 \\
\hline
\end{tabular}

C)

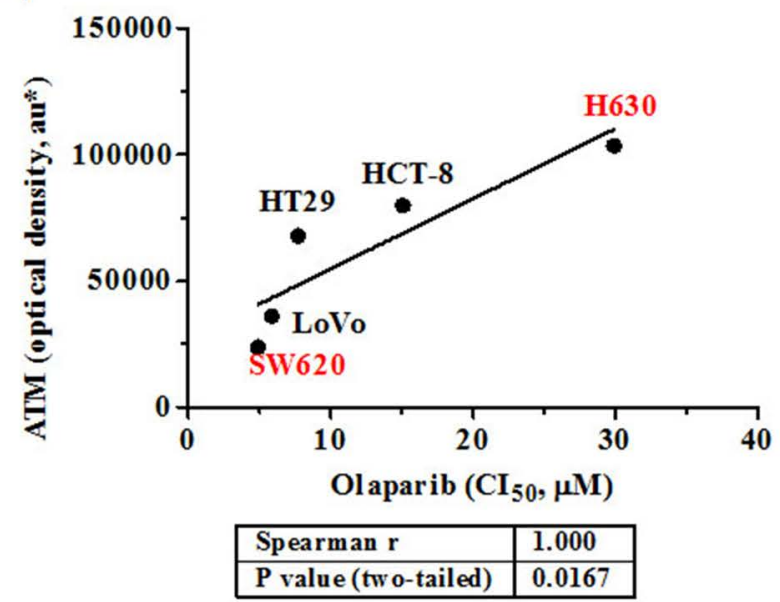

B)



D)

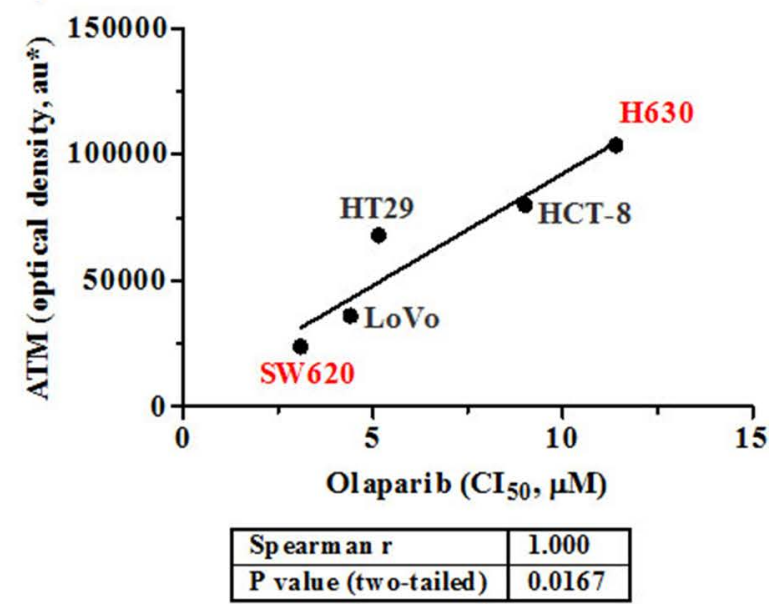

Figure 3. Correlations between baseline ATM expression and HYDAMTIQ $\mathrm{IC}_{50}$ values in colon carcinoma cell lines. Scatter plots indicate relationships between baseline ATM expression and $\mathrm{IC}_{50}$ of HYDAMTIQ at 144 (A) and 240 (B) h or IC ( $_{50}$ of olaparib at 144 (C) and 240 (D) h in cell lines. *au, arbitrary units, mean \pm standard error. Black circles indicate the intersection of IC ${ }_{50} / \mathrm{ATM}^{*}$ expression values of a single cell line.

activity of HYDAMTIQ has been so far investigated in in vivo inflammatory models only ${ }^{10-12}$.

Our study showed that HYDAMTIQ and olaparib were more active in the BRCA2-mutated CAPAN-1 human pancreatic cancer cell line than in the wild-type $B R C A 2$, cisplatin-resistant CAPAN-1 clones (i.e., C2-6, C2-12, and C2-14) and in the BRCA1/2 wild-type MCF-7 breast cancer cell line. No difference in the activity of HYDAMTIQ or olaparib was observed in cell lines with different MS or MRE11 status.

HYDAMTIQ and olaparib were more active in SW620 human colorectal cancer cells characterized by a low ATM protein expression than in H630 human colorectal cancer cells with high ATM protein levels. Following exposure to HYDAMTIQ, ATM protein levels decreased in both study cell lines, although a more marked decrease was observed in SW620 cells. In the same low- and high-ATM expression cell lines, the potential synergistic effect of the combination of 5-FU and HYDAMTIQ or olaparib was evaluated. In SW620 cells, the combination of 5-FU and HYDAMTIQ or olaparib exerted a synergistic effect, whereas an antagonistic effect in H630 cells was observed.

The major determinant of the PARPI activity is the presence of defects in the DNA repair mechanisms of cancer cells. In particular, PARPIs are selectively cytotoxic against cells with mutations of genes involved in DNA repair (synthetic lethality) $^{21,22,28}$. The absence of defects in DNA repair mechanisms does not allow an optimal inhibitory effect on the growth of PARPIs. Ovarian, breast, and pancreatic cancers with mutations in $B R C A 1$ or $B R C A 2$ genes involved in the HRR system have been shown to be sensitive to the activity of PARPIs both at preclinical 
A)

\begin{tabular}{cccc}
\hline & Cell line & $\mathrm{IC}_{60}, \mu \mathrm{NI}$ & $\mathrm{r}$ \\
\hline$\bullet$ & SW620 & 10.5 & \\
$\rightarrow$ & H630 & 20.4 & 0.5 \\
\hline
\end{tabular}

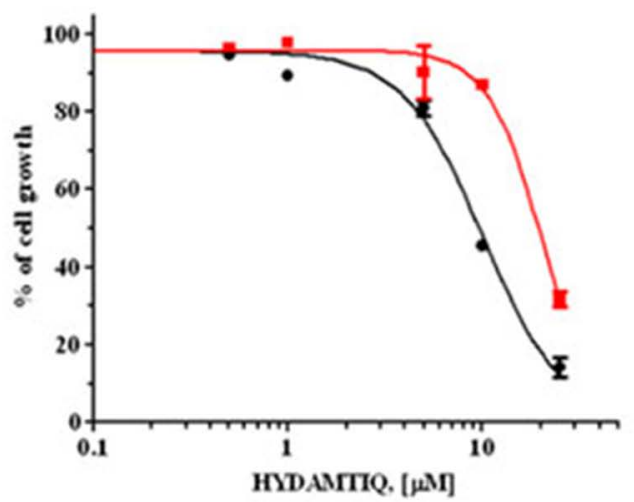

C)

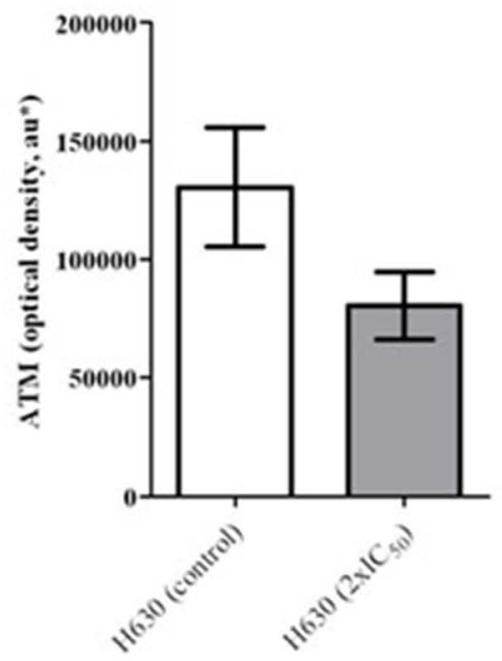

B)

\begin{tabular}{cccc}
\hline & Cell line & $\mathrm{IC}_{b 0}, \mu \mathrm{VI}$ & $\mathrm{r}$ \\
\hline$\bullet$ & SW620 & 3.1 & \\
$\bullet-$ & $\mathrm{H630}$ & 11.4 & 0.3 \\
\hline
\end{tabular}

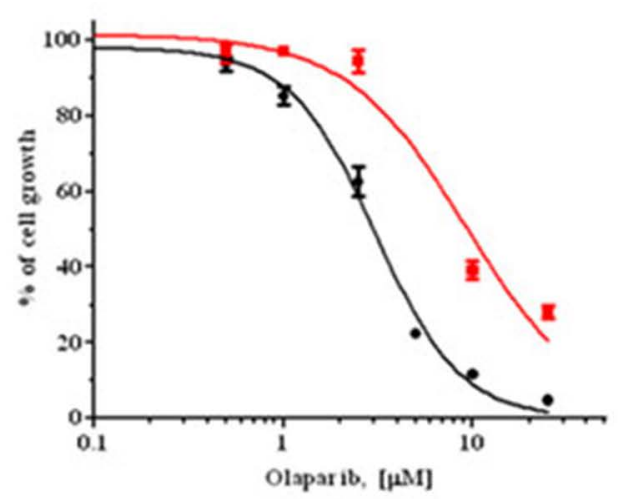

D)

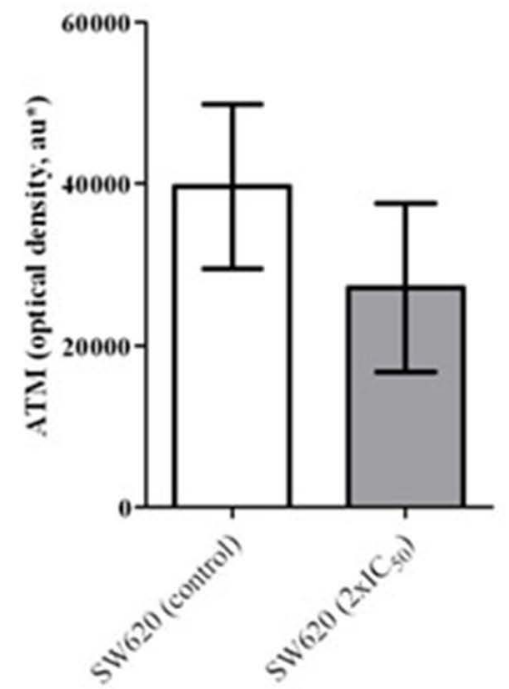

Figure 4. Dose-dependent effects of HYDAMTIQ and olaparib in SW620 and H630 cell lines and changes of ATM levels following $2 \times \mathrm{IC}_{50}$ HYDAMTIQ treatment. Inhibition of cell growth: dose-dependent effects of HYDAMTIQ (A) or olaparib (B) in cell lines with the highest (H630) or the lowest (SW620) level of ATM protein. Inhibitory cell growth effects were evaluated after $240 \mathrm{~h}$ of exposure. ATM protein expression levels in H630 (C) and SW620 (D) cells exposed to HYDAMTIQ $2 \times \mathrm{IC}_{50}$ for $240 \mathrm{~h}$. *au, arbitrary units, mean \pm standard error.

and clinical levels ${ }^{29}$. As expected, our results showed a more potent activity of HYDAMTIQ in BRCA2-mutated cells than in BRCA wild-type cells and are in agreement with those reported by Sakai et al. ${ }^{30}$ concerning the PARPI AG014361 in the same in vitro tumor models. Other authors also reported a higher activity of different PARPIs, such as talazoparib $^{31}$ or AG014699 32 , in CAPAN-1 cells or other $B R C A 1 / 2$-mutated or epigenetically silenced $B R C A 1 / 2$ cell lines compared to $B R C A 1 / 2$ wild-type cell lines.

PARPIs can also contribute to synthetic lethality in MSI cancer cells. MSI is a molecular phenotype that arises from defects in the DNA mismatch repair (MMR) system. Loss of MMR function is due to somatic or germline epigenetic/genetic alterations of $M M R$ genes. About $15 \%$ of colorectal cancers show MSI due to epigenetic silencing of the $M L H 1$ gene or to germline mutations in mismatch repair genes (e.g., $M L H 1, M S H 2, M S H 6)^{33}$. Other mutations that contribute to the MSI phenotype may be present in oncogenes and tumor suppressor genes, in particular $B R A F^{34}, M R E 11$ (ATM) ${ }^{35,36}$, and $K R A S^{37}$.

Our findings, showing no difference in the activity of HYDAMTIQ or olaparib in colorectal cancer cell lines as a function of both MS and MRE11 status, are in agreement with those obtained by Genther Williams et al. ${ }^{38}$, who observed no difference in the sensitivity to niraparib between MSI-H and MSS colorectal cancer cell lines. 
A)

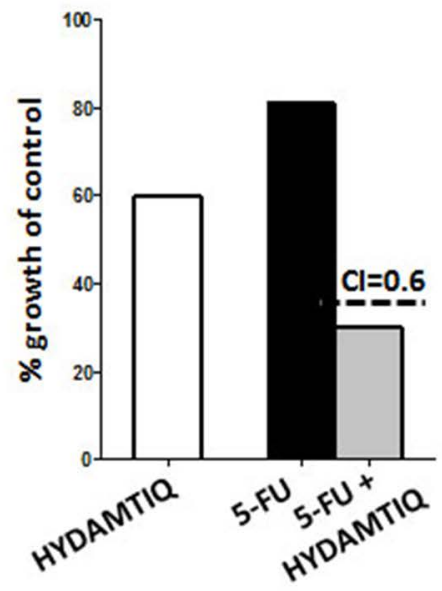

C)

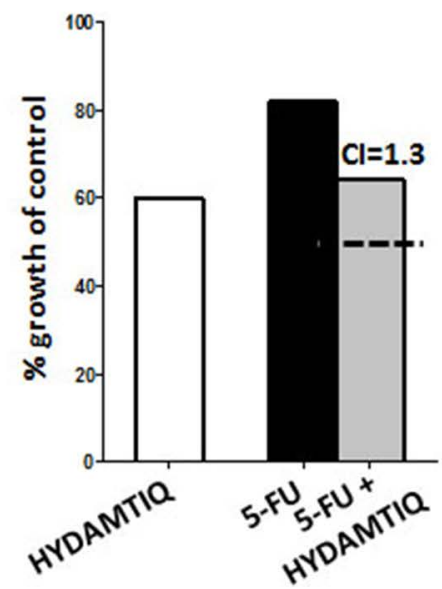

B)

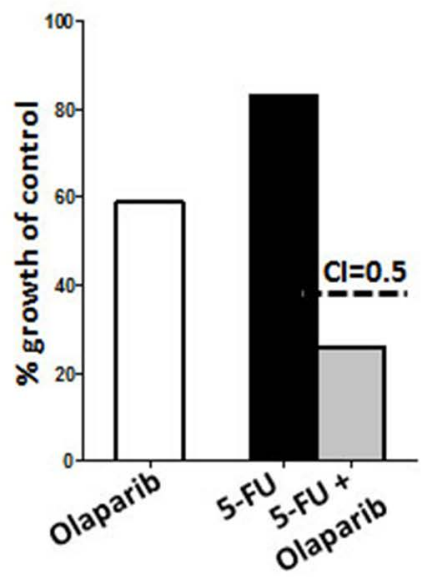

D)

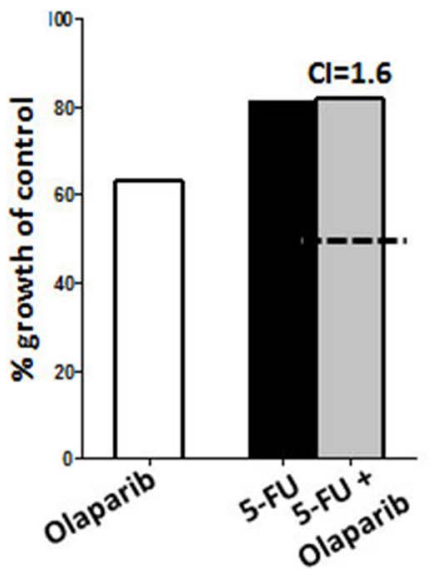

Figure 5. Pharmacodynamic interactions between HYDAMTIQ or olaparib and 5-fluorouracil in SW620 and H630 cell lines. Synergistic inhibitory effects of HYDAMTIQ $20 \mu \mathrm{M}\left(\sim \mathrm{IC}_{50}\right)$ (white bar), 5-FU $3 \mu \mathrm{M}\left(\sim \mathrm{IC}_{25}\right)$ (black bar), HYDAMTIQ $20 \mu \mathrm{M}$ plus 5 -FU $3 \mu \mathrm{M}$ (gray bar) (A) or olaparib $5 \mu \mathrm{M}\left(\sim \mathrm{IC}_{50}\right)$ (white bar), 5-FU $3 \mu \mathrm{M}\left(\sim \mathrm{IC}_{25}\right)$ (black bar), and olaparib $5 \mu \mathrm{M}$ plus 5 -FU $3 \mu \mathrm{M}$ (gray bar) (B) on the growth of SW620 cells characterized by low levels of ATM after $144 \mathrm{~h}$ of exposure. Antagonistic inhibitory effects of HYDAMTIQ $45 \mu \mathrm{M}\left(\sim \mathrm{IC}_{50}\right)$ (white bar), 5-FU $1 \mu \mathrm{M}\left(\sim \mathrm{IC}_{25}\right)$ (black bar), HYDAMTIQ $45 \mu \mathrm{M}$ plus 5-FU $1 \mu \mathrm{M}$ (gray bar) (C) or olaparib $30 \mu \mathrm{M}\left(\sim \mathrm{IC}_{50}\right)$ (white bar), 5-FU $1 \mu \mathrm{M}\left(\sim \mathrm{IC}_{25}\right)$ (black bar), and olaparib $30 \mu \mathrm{M}$ plus 5 -FU $1 \mu \mathrm{M}$ (gray bar) (D) on the growth of $\mathrm{H} 630$ cells characterized by high levels of ATM after $144 \mathrm{~h}$ of exposure. Data from a representative experiment. The dotted line indicates expected growth. CI, observed/expected growth ratio.

Similar findings were observed by McPherson et al. ${ }^{36}$ in panels of colorectal cancer cell lines with different MS status treated with the PARPI LT-626. Conversely, Vilar et al. ${ }^{35}$ showed a higher sensitivity to the PARPI veliparib in MSI MRE11 mutated colorectal cancer cells compared with MSS MRE11 wild-type colorectal cancer cells. Differences observed between our results and those of Vilar et al. could be due to the different colorectal cancer cells used. In fact, only four out of their eight cell lines were included in our seven cell line panel.

The concept of "synthetic lethality" may also be extended to ATM that is frequently altered or deleted both in solid and hematologic malignancies. Heterozygous germline mutations in ATM are associated with leukemia, breast, and pancreatic cancers ${ }^{39}$. ATM is a serine threonine kinase that represents a critical component of the early response to DNA damage and activation of cell cycle checkpoints $^{40}$. ATM, together with ATR, collaborates with the checkpoint proteins Chk2 and Chk1, respectively, to arrest the cell cycle and allow DNA repair. Several studies have shown that ATM deficiency or ATM harboring mutations confer sensitivity to olaparib in in vitro lymphoid tumor models ${ }^{41-43}$ and in breast ${ }^{44}$, gastric ${ }^{45}$, and colorectal ${ }^{46}$ cancer cells. The HYDAMTIQ activity results in SW620 and H630 cells, selected from a panel of human colorectal cancer cell lines on the basis of their ATM protein 
expression levels (i.e., the lowest and highest, respectively), are in agreement with data from the studies reported above, performed in in vitro models treated by olaparib ${ }^{41,43-46}$. To investigate a potential differential role for ATM protein levels according to HYDAMTIQ treatment, we evaluated variations in ATM protein levels in SW620 and H630 cells pre- and posttreatment. We observed a more marked decrease in posttreatment ATM in SW620 cells, suggesting that other molecular mechanisms, in addition to ATM, are likely involved in resistance to HYDAMTIQ.

In addition to the above-reported conditions, mainly represented by defects in DNA repair pathways and DNA damage recognition, signaling, and checkpoints system that allow PARPIs to exploit synthetic lethality, this phenomenon may also be generated by the concomitant presence of PARPIs and DNA-damaging agents. In fact, it has been observed that the suppression of PARP activity increases cell susceptibility to DNA-damaging agents and inhibits strand break rejoining. Thus, the inhibition of PARP could represent an interesting pharmacological strategy in order to enhance the effectiveness of DNA damage induced, for instance, by $5-\mathrm{FU}$, a pyrimidine antimetabolite that is the backbone of the treatment of colorectal cancer both in the adjuvant and metastatic setting $^{47}$. In particular, 5-FU determines imbalances in deoxynucleotide triphosphate levels as well as the accumulation of uracil and 5-FU at the genomic level. Such events are able to activate the ATR- and ATM-dependent checkpoint signaling pathways and the BER pathway.

Although the ATR- and ATM-dependent checkpoint signaling pathways are activated by $5-\mathrm{FU}$, their role in the survival of cancer cells treated with this drug is still unclear $^{48}$. The observed synergistic effect of the combination of 5-FU and HYDAMTIQ or olaparib in SW620 cells and the observed antagonistic effect in H630 cells support the hypothesis that low ATM expression may be associated with impaired DNA repair while high ATM expression may not be.

To date, few articles have investigated the effects of in vitro combinations, including PARPIs and 5-FU, with controversial results ${ }^{48-52}$. Sakogawa et al. ${ }^{50}$ studied the histone variant $\mathrm{cH} 2 \mathrm{AX}$ as a marker of DSBs and found that combined treatment with 5-FU and the PARPI 3 -aminobenzamide (3-AB) induced $\mathrm{cH} 2 \mathrm{AX}$ focus formation with similar increases and kinetics as the single treatment with 5-FU in esophageal cancer cells. These authors then suggested that, in combination with 5-FU, PARPIs would not be able to increase DSB. On the contrary, Falzacappa et al. ${ }^{52}$ showed that PARP inhibition by rucaparib enhances the chemosensitization of both myeloid (OCI-AML2) and lymphoid (RPMI-8402) leukemia cells to 5-FU exposure, suggesting a synergistic effect of the combined therapy in killing leukemia cells. Based on the above observations, further studies are therefore needed to clarify the relationship between ATM, 5-FU, and PARPIs.

The results of our in vitro studies have shown that the novel PARPI HYDAMTIQ exhibits potent cell growth inhibitory activity against a limited number of tumor cell lines with relevant defects in DDR pathways. In these in vitro models, HYDAMTIQ showed comparable antiproliferative effects to olaparib.

The spectrum of antiproliferative activity of HYDAMTIQ remains to be determined on a wider panel of tumor types with particular reference to human cell lines with defects in other HRR proteins recruited by PARP (e.g., XRCC1, topoisomerase I). Thus, a molecular target screen of HYDAMTIQ in a large cell line set with known mutational profile of genes involved in the DNA repair process is warranted and will allow more informed interpretation of HYDAMTIQ spectrum of activity.

These results could be of particular clinical relevance since genetic/epigenetic alterations of these genes have been observed in several types of tumors, providing a basis for preclinical and potential clinical development of PARP inhibition in tumors other than ovarian and breast cancers, such as prostate and pancreatic tumors, and glioblastoma multiforme ${ }^{53}$.

Also, pharmacokinetics/pharmacodynamics (PK/PD) and maximum tolerated dose (MTD) studies for HYDAMTIQ screening in selected preclinical in vivo cancer models are warranted prior to first-in-human trials in patients with mixed solid, refractory, metastatic tumors and further potential proof-of-concept trials in the chosen tumor settings. It is conceivable that these studies are feasible since HYDAMTIQ displays favorable physicochemical and PK properties, in particular a good brain penetration supporting, for instance, potential application in glioblastoma (Pellicciari, unpublished data).

Clinical development of PARPIs also comprises the approach of combining PARPIs with DNA-damaging agents to achieve chemosensitization. This is based on extensive preclinical studies showing that PARPIs enhance the action of temozolomide, cisplatin, topoisomerase I inhibitors, and ionizing radiation in tumor cell lines in vitro and in mouse xenograft models of human cancers. Our study also provides evidence of synergism of HYDAMTIQ and a fluoropyrimidine, 5-FU. These findings suggest that combining a fluoropyrimidine and a PARPI may be an innovative therapeutic strategy for colorectal cancer. Phase I and II trials of various PARPIs in combination with DNA-damaging agents are ongoing.

In this scenario, it will be interesting to see whether HYDAMTIQ is equivalent or superior to the various PARP-1/2 inhibitors currently in clinical development as either single-agent or combination therapy. Thus, further basic studies of this novel potent PARPI are warranted and are likely to be informative and worthwhile. 
ACKNOWLEDGMENTS: This study was supported by contributions from the Associazione Italiana per la Ricerca sul Cancro (IG No. 15565), Milan (to E. Mini), Ente Cassa di Risparmio di Firenze, Florence (No. 2009/0767 to E. Masini and F. Moroni, No. 2012/0744 to E. Masini, No. 2014/0706 to E. Mini, and No. 2014/0969 to S. Nobili), Associazione Giacomo Onlus, Castiglioncello (to E. Mini), and Gruppo Oncologico Chirurgico Cooperativo Italiano, Florence (to E. Mini).

\section{REFERENCES}

1. Kraus WL. PARPs and ADP-ribosylation: 50 years...and counting. Mol Cell 2015;58(6):902-10.

2. Barkauskaite E, Jankevicius G, Ahel I. Structures and mechanisms of enzymes employed in the synthesis and degradation of PARP-dependent protein ADP-ribosylation. Mol Cell 2015;58(6):935-46.

3. Boehler C, Gauthier LR, Mortusewicz O, Biard DS, Saliou JM, Bresson A, Sanglier-Cianferani S, Smith S, Schreiber V, Boussin F, Dantzer F. Poly(ADP-ribose) polymerase 3 (PARP3), a newcomer in cellular response to DNA damage and mitotic progression. Proc Natl Acad Sci USA 2011;108(7):2783-8.

4. Cerrato A, Morra F, Celetti A. Use of poly ADP-ribose polymerase [PARP] inhibitors in cancer cells bearing DDR defects: The rationale for their inclusion in the clinic. J Exp Clin Cancer Res. 2016;35(1):179.

5. Kaufman B, Shapira-Frommer R, Schmutzler RK, Audeh MW, Friedlander M, Balmaña J, Mitchell G, Fried G, Stemmer SM, Hubert A, Rosengarten O, Steiner M, Loman N, Bowen K, Fielding A, Domchek SM. Olaparib monotherapy in patients with advanced cancer and a germline BRCA1/2 mutation. J Clin Oncol. 2015;33(3):244-50.

6. Swisher EM, Lin KK, Oza AM, Scott CL, Giordano H, Sun J, Konecny GE, Coleman RL, Tinker AV, O’Malley DM, Kristeleit RS, Ma L, Bell-McGuinn KM, Brenton JD, Cragun JM, Oaknin A, Ray-Coquard I, Harrell MI, Mann E, Kaufmann SH, Floquet A, Leary A, Harding TC, Goble S, Maloney L, Isaacson J, Allen AR, Rolfe L, Yelensky R, Raponi M, McNeish IA. Rucaparib in relapsed, platinumsensitive high-grade ovarian carcinoma (ARIEL2 Part 1): An international, multicentre, open-label, phase 2 trial. Lancet Oncol. 2017;18(1):75-87.

7. Patel AG, Sarkaria JN, Kaufmann SH. Nonhomologous end joining drives poly(ADP-ribose) polymerase (PARP) inhibitor lethality in homologous recombination-deficient cells. Proc Natl Acad Sci USA 2011;108(8):3406-11.

8. Moroni F, Formentini L, Gerace E, Camaioni E, PellegriniGiampietro DE, Chiarugi A, Pellicciari R. Selective PARP-2 inhibitors increase apoptosis in hippocampal slices but protect cortical cells in models of post-ischaemic brain damage. Br J Pharmacol. 2009;157(5):854-62.

9. Pellicciari R, Camaioni E, Gilbert AM, Macchiarulo A, Bikker JA, Shah F, Bard J, Costantino G, Gioiello A, Robertson GM, Sabbatini P, Venturoni F, Liscio P, Carotti A, Bellocchi D, Cozzi A, Wood A, Gonzales C, Zaleska MM, Ellingboe JW, Moroni F. Discovery and characterization of novel potent PARP-1 inhibitors endowed with neuroprotective properties: From TIQ-A to HYDAMTIQ. Med Chem Commun. 2011;2:559-65.

10. Moroni F, Cozzi A, Chiarugi A, Formentini L, Camaioni E, Pellegrini-Giampietro DE, Chen Y, Liang S, Zaleska MM, Gonzales C, Wood A, Pellicciari R. Long-lasting neuroprotection and neurological improvement in stroke models with new, potent and brain permeable inhibitors of poly(ADP-ribose) polymerase. Br J Pharmacol. 2012; 165(5):1487-500.

11. Lucarini L, Pini A, Gerace E, Pellicciari R, Masini E, Moroni F. Poly(ADP-ribose) polymerase inhibition with HYDAMTIQ reduces allergen-induced asthma-like reaction, bronchial hyper-reactivity and airway remodelling. J Cell Mol Med. 2014;18(3):468-79.

12. Lucarini L, Durante M, Lanzi C, Pini A, Boccalini G, Calosi L, Moroni F, Masini E, Mannaioni G. HYDAMTIQ, a selective PARP-1 inhibitor, improves bleomycin-induced lung fibrosis by dampening the TGF-b/SMAD signalling pathway. J Cell Mol Med. 2017;21(2):324-35.

13. Tutt A, Robson M, Garber JE, Domchek SM, Audeh MW, Weitzel JN, Friedlander M, Arun B, Loman N, Schmutzler RK, Wardley A, Mitchell G, Earl H, Wickens M, Carmichael J. Oral poly(ADP-ribose) polymerase inhibitor olaparib in patients with BRCA1 or BRCA2 mutations and advanced breast cancer: A proof-of-concept trial. Lancet 2010;376(9737):235-44.

14. Audeh MW, Carmichael J, Penson RT, Friedlander M, Powell B, Bell-McGuinn KM, Scott C, Weitzel JN, Oaknin A, Loman N, Lu K, Schmutzler RK, Matulonis U, Wickens M, Tutt A. Oral poly(ADP-ribose) polymerase inhibitor olaparib in patients with BRCA1 or BRCA2 mutations and recurrent ovarian cancer: A proof-of-concept trial. Lancet 2010;376(9737):245-51.

15. Skehan P, Storeng R, Scudiero D, Monks A, McMahon J, Vistica D, Warren JT, Bokesch H, Kenney S, Boyd MR. New colorimetric cytotoxicity assay for anticancer-drug screening. J Natl Cancer Inst. 1990;82(13):1107-12.

16. Drewinko B, Loo TL, Brown B, Gottlieb JA, Freireich EJ. Combination chemotherapy in vitro with adriamycin. Observations of additive, antagonistic, and synergistic effects when used in two-drug combinations on cultured human lymphoma cells. Cancer Biochem Biophys. 1976;1 (4):187-95.

17. Schreiber V, Dantzer F, Ame JC, de Murcia G. Poly(ADPribose): Novel functions for an old molecule. Nat Rev Mol Cell Biol. 2006;7(7):517-28.

18. Li M, Yu X. The role of poly(ADP-ribosyl)ation in DNA damage response and cancer chemotherapy. Oncogene 2015; 34(26):3349-56.

19. De Vos M, Schreiber V, Dantzer F. The diverse roles and clinical relevance of PARPs in DNA damage repair: Current state of the art. Biochem Pharmacol. 2012;84(2): $137-46$

20. Lapucci A, Pittelli M, Rapizzi E, Felici R, Moroni F, Chiarugi A. Poly(ADP-ribose) polymerase-1 is a nuclear epigenetic regulator of mitochondrial DNA repair and transcription. Mol Pharmacol. 2011;79(6):932-40.

21. Curtin NJ. DNA repair dysregulation from cancer driver to therapeutic target. Nat Rev Cancer 2012;12(12):801-17.

22. O'Connor MJ. Targeting the DNA damage response in cancer. Mol Cell 2015;60(4):547-60.

23. Maréchal A, Zou L. DNA damage sensing by the ATM and ATR kinases. Cold Spring Harb Perspect Biol. 2013;5(9): pii:a012716.

24. Ruf A, de Murcia G, Schulz. Inhibitor and NAD+ binding to poly(ADP-ribose) polymerase as derived from crystal structures and homology modeling. Biochemistry 1998; 37(11):3893-900.

25. Murai J, Huang SY, Das BB, Renaud A, Zhang Y, Doroshow JH, Ji J, Takeda S, Pommier Y. Trapping of 
PARP1 and PARP2 by clinical PARP inhibitors. Cancer Res. 2012;72(21):5588-99.

26. Liscio P, Camaioni E, Carotti A, Pellicciari R, Macchiarulo A. From polypharmacology to target specificity: The case of PARP inhibitors. Curr Top Med Chem. 2013;13(23): 2939-54.

27. Thompson JM, Nguyen QH, Singh M, Razorenova OV. Approaches to identifying synthetic lethal interactions in cancer. Yale J Biol Med. 2015;88(2):145-55.

28. Lord CJ1, Tutt AN, Ashworth A. Synthetic lethality and cancer therapy: Lessons learned from the development of PARP inhibitors. Annu Rev Med. 2015;66:455-70.

29. Scott CL, Swisher EM, Kaufmann SH. Poly (ADP-ribose) polymerase inhibitors: Recent advances and future development. J Clin Oncol. 2015;33(12):1397-406.

30. Sakai W, Swisher EM, Karlan BY, Agarwal MK, Higgins J, Friedman C, Villegas E, Jacquemont C, Farrugia DJ, Couch FJ, Urban N, Taniguchi T. Secondary mutations as a mechanism of cisplatin resistance in BRCA2-mutated cancers. Nature 2008;451(7182):1116-20.

31. Wang B, Chu D, Feng Y, Shen Y, Aoyagi-Scharber M, Post LE. Discovery and characterization of (8S,9R)-5-fluoro8-(4-fluorophenyl)-9-(1-methyl-1H-1,2,4-triazol-5-yl)2,7,8,9-tetrahydro-3H-pyrido[4,3,2-de]phthalazin-3-one (BMN 673, Talazoparib), a novel, highly potent, and orally efficacious poly(ADP-ribose) polymerase-1/2 Inhibitor, as an anticancer agent. J Med Chem. 2016;59(1):335-57.

32. Drew Y, Mulligan EA, Vong WT, Thomas HD, Kahn S, Kyle S, Mukhopadhyay A, Los G, Hostomsky Z, Plummer ER, Edmondson RJ, Curtin NJ. Therapeutic potential of poly(ADP-ribose) polymerase inhibitor AG014699 in human cancers with mutated or methylated BRCA1 or BRCA2. J Natl Cancer Inst. 2011;103(4):334-46.

33. Gelsomino F, Barbolini M, Spallanzani A, Pugliese G, Cascinu S. The evolving role of microsatellite instability in colorectal cancer: A review. Cancer Treat Rev. 2016;51: 19-26.

34. Gallois C, Laurent-Puig P, Taieb J. Methylator phenotype in colorectal cancer: A prognostic factor or not? Crit Rev Oncol Hematol. 2016;99:74-80.

35. Vilar E, Bartnik CM, Stenzel SL, Raskin L, Ahn J, Moreno V, Mukherjee B, Iniesta MD, Morgan MA, Rennert G, Gruber SB. MRE11 deficiency increases sensitivity to poly(ADPribose)polymerase inhibition in microsatellite unstable colorectal cancers. Cancer Res. 2011;71:2632-42.

36. McPherson LA, Shen Y, Ford JM. Poly (ADP-ribose) polymerase inhibitor LT-626: Sensitivity correlates with MRE11 mutations and synergizes with platinums and irinotecan in colorectal cancer cells. Cancer Lett. 2014; 343(2):217-23.

37. Lin EI, Tseng LH, Gocke CD, Reil S, Le DT, Azad NS, Eshleman JR. Mutational profiling of colorectal cancers with microsatellite instability. Oncotarget 2015;6(39): 42334-44.

38. Genther Williams SM, Kuznicki AM, Andrade P, Dolinski BM, Elbi C, O'Hagan RC, Toniatti C. Treatment with the PARP inhibitor, niraparib, sensitizes colorectal cancer cell lines to irinotecan regardless of MSI/MSS status. Cancer Cell Int. 2015;15(1):14

39. Thompson D, Duedal S, Kirner J, McGuffog L, Last J, Reiman A, Byrd P, Taylor M, Easton DF. Cancer risks and mortality in heterozygous ATM mutation carriers. J Natl Cancer Inst. 2005;97(11):813-22.
40. Shiloh Y, Ziv Y. The ATM protein kinase: Regulating the cellular response to genotoxic stress, and more. Nat Rev Mol Cell Biol. 2013;14:197-210.

41. Williamson CT, Muzik H, Turhan AG, Zamò A, O'Connor MJ, Bebb DG, Lees-Miller SP. ATM deficiency sensitizes mantle cell lymphoma cells to poly(ADP-ribose) polymerase-1 inhibitors. Mol Cancer Ther. 2010;9(2):347-57.

42. Weston VJ, Oldreive CE, Skowronska A, Oscier DG, Pratt G, Dyer MJ, Smith G, Powell JE, Rudzki Z, Kearns P, Moss PA, Taylor AM, Stankovic T. The PARP inhibitor olaparib induces significant killing of ATM-deficient lymphoid tumor cells in vitro and in vivo. Blood 2010;116(22):4578-87.

43. Williamson CT, Kubota E, Hamill JD, Klimowicz A, Ye R, Muzik H, Dean M, Tu LR, Gilley D, Magliocco AM, McKay BC, Bebb DG, Lees-Miller SP. Enhanced cytotoxicity of PARP inhibition in mantle cell lymphoma harbouring mutations in both ATM and p53. EMBO Mol Med. 2012;4(6):515-27.

44. Gilardini Montani MS, Prodosmo A, Stagni V, Merli D, Monteonofrio L, Gatti V, Gentileschi MP, Barilà D, Soddu S. ATM-depletion in breast cancer cells confers sensitivity to PARP inhibition. J Exp Clin Cancer Res. 2013;32:95.

45. Kubota E, Williamson CT, Ye R, Elegbede A, Peterson L, Lees-Miller SP, Bebb DG. Low ATM protein expression and depletion of p53 correlates with olaparib sensitivity in gastric cancer cell lines. Cell Cycle 2014;13(13):2129-37.

46. Wang C, Jette N, Moussienko D, Bebb DG, Lees-Miller SP. ATM-deficient colorectal cancer cells are sensitive to the PARP inhibitor olaparib. Transl Oncol. 2017;10(2):190-6.

47. Pettersen HS, Visnes T, Vågbø CB, Svaasand EK, Doseth B, Slupphaug G, Kavli B, Krokan HE. UNG-initiated base excision repair is the major repair route for 5-fluorouracil in DNA, but 5-fluorouracil cytotoxicity depends mainly on RNA incorporation. Nucleic Acids Res. 2011;39(19):8430-44.

48. Huehls AM, Wagner JM, Huntoon CJ, Geng L, Erlichman C, Patel AG, Kaufmann SH, Karnitz LM. Poly(ADPRibose) polymerase inhibition synergizes with 5-fluorodeoxyuridine but not 5-fluorouracil in ovarian cancer cells. Cancer Res. 2011;71(14):4944-54.

49. Geng L, Huehls AM, Wagner JM, Huntoon CJ, Karnitz LM. Checkpoint signaling, base excision repair, and PARP promote survival of colon cancer cells treated with 5-fluorodeoxyuridine but not 5-fluorouracil. PLoS One 2011;6(12):e28862.

50. Sakogawa K, Aoki Y, Misumi K, Hamai Y, Emi M, Hihara J, Shi L, Kono K, Horikoshi Y, Sun J, Ikura T, Okada M, Tashiro S. Involvement of homologous recombination in the synergism between cisplatin and poly (ADP-ribose) polymerase inhibition. Cancer Sci. 2013;104(12):1593-9.

51. Shekh K, Khan S, Jena G, Kansara BR, Kushwaha S. 3-Aminobenzamide-A PARP inhibitor enhances the sensitivity of peripheral blood micronucleus and comet assays in mice. Toxicol Mech Methods 2014;24(5):332-41.

52. Falzacappa MV, Ronchini C, Faretta M, Iacobucci I, Di Rorà AG, Martinelli G, Meyer LH, Debatin KM, Orecchioni S, Bertolini F, Pelicci PG. The combination of the PARP inhibitor rucaparib and $5 \mathrm{FU}$ is an effective strategy for treating acute leukemias. Mol Cancer Ther. 2015;14(4):889-98.

53. Lord CJ, Ashworth A. BRCAness revisited. Nat Rev Cancer 2016;16(2):110-20. 